\title{
Discussions on Strategies for Developing Students' Cooperative Awareness in Music Teaching
}

\author{
Jibin $\mathrm{Wu}$ \\ Fuqing Branch, Fujian Normal University, Fuzhou Fujian, 350300, China
}

Key words: Music teaching, Preschool education major; Cooperative awareness.

\begin{abstract}
Developing students' cooperative awareness in music teaching will facilitate students in in-depth study of musical knowledge in solidarity and cooperation, and achieving good learning outcome. Hence, music teachers should pay more attention to the cultivation of students' cooperative awareness in teaching practice, and improve students' music learning ability via the cultivation of students' cooperative awareness, to guarantee the improvement of teaching quality. This paper aims, from the angle of cultivation of students' cooperative awareness in music teaching of preschool education major, to provide certain support to the enhancement of the comprehensive musical quality of preschool education majors.
\end{abstract}

\section{Introduction}

With the social development and as the social demands and requirements for talents become increasingly strict in the new era, the cultivation of cooperative awareness of talents in teaching gradually becomes the priority. Only by paying more attention to the cultivation of students' cooperative awareness, and positively exploring scientific education measures to strengthen students' cooperative awareness and capability, students can adapt themselves to working life after graduation, and cooperate with other colleagues to fulfill tasks. Hence, teachers of preschool education major in universities should lay stress on the permeation of cooperative awareness, and take measures to cultivate students' cooperative awareness, to provide a guarantee for the future development of students while improving the music teaching quality of preschool education major.

\section{Defects of Cultivation of Cooperative Awareness in Music Teaching of Preschool Education Major at the Present Stage}

Under the influence of the new curriculum reform idea, music teacher of preschool education major start realizing the importance of cultivating students' comprehensive quality, and promoting the all-around development of students, and consciously explore relatively scientific teaching measures in teaching practice to cultivate students' independent study and cooperative learning awareness, but the teaching effect is not satisfactory on the whole. There are certain problems in the cultivation of students' cooperative awareness which adversely influence students' all-around development.

\section{Sameness of Teaching Method}

Presently, music teachers of preschool education major have slightly innovated the teaching method based on the requirements for trait-oriented education, and actively changed their traditional duck-stuffing teaching method, and students also actively participate in classroom teaching activities, and students' enthusiasm for and capability of music learning have been constantly enhanced. Nevertheless, the innovated teaching method still appears to be dull, which is effective to arouse students' enthusiasm for and independence of learning but weak in cultivating students' cooperative awareness. Although students participate in classroom activities, they seldom interactive or communicate with teacher and other classmates, which largely impedes the cultivation of students' cooperative awareness, and has adverse effect on the cultivation of preschool education majors' comprehensive quality. 


\section{Lack of Atmosphere of Cultivation of Cooperative Awareness in Classroom}

The music learning of preschool education majors are relatively special, requiring students should have certain musical knowledge foundation and music education ability, be capable of cooperating with children in learning under the driving of cooperative awareness in early childhood education, and perform cultivation of children's music knowledge and culture under the guidance of cooperative awareness. Hence, preschool education majors are required to have a cooperative awareness. But the music teachers of preschool education major have not realized the significance of the cultivation of students' cooperative awareness, and don't aim to create an atmosphere of cooperative awareness in classroom teaching, and students hardly can develop and improve their cooperative awareness. Most students cannot cooperate or interact with other classmates in learning. These factors have certain adverse influence on the enhancement of professional quality of students.

\section{Less Systematicness of Teaching}

That the music teaching of preschool education major is less systematic also has adverse influence on the cultivation of students' cooperative awareness. Specifically, some teachers of preschool education major have gradually realized the importance of cultivating students' cooperative awareness through teaching practice, and are trying to explore the cultivation of students' cooperative awareness in music teaching process, with a hope to constantly enhance students' cooperative awareness. Yet there lacks system theoretical guidance, so the teaching of cultivating students' cooperative awareness carried out by teachers appears to be much less systematic. They can help students develop a cooperative awareness to a certain extent, but not truly form the cooperative awareness and capability. The systematicness of teaching and cultivation of cooperative awareness should be further strengthened.

\section{Deflects in Teaching Staff Construction}

Under the influence of the traditional educational idea, the cultivation of students' music quality in the process of preschool education major training in China has been ignored. Music teachers of preschool education major are insufficiently manned, most music teachers' comprehensive quality level is low, and even some teachers are incapable of independently innovating music teaching activities but fulfill cultivation of students' cooperative awareness under the guidance of others. Under such circumstances, the effect of cultivation of preschool education majors' cooperative awareness in music teaching is poor, which is adverse to the all-around development of students, and restrains the optimization of students' career of preschool education in future.

\section{Measures for Cultivation of Preschool Education Majors' Cooperative Awareness in Music Teaching in the New Era}

The defects in the cultivation of preschool education majors' cooperative awareness in music teaching have been set forth above. To rationally cultivate students' cooperative awareness in the new era, scientific measures should be explored on this basis, so as to gradually improve the current situation of cultivation of preschool education majors' cooperative awareness, promote students' cooperative awareness to be enhanced, and provide a guarantee for students' all-around development in future.

\section{Improvement of Teachers' Comprehensive Quality through Scientific Education and Training}

The improvement of teachers' comprehensive quality is the guarantee for the improvement of teaching quality and scientificity. Only by constantly improving music teachers' professional teaching quality through training, it can be guaranteed that teachers have the capability of cultivating students' cooperative awareness, namely setting rational teaching contents and selecting proper teaching methods for cultivation of preschool education majors' cooperative awareness in music teaching, to gradually fulfill the task of cultivating students' cooperative awareness and train 
preschool education majors to be high-quality talents meeting society demands ${ }^{[1]}$. On this basis, related normal colleges should offer education training to music teachers of preschool education major regularly, to train them to master new education thoughts and ideas, combine advanced education thoughts to create specific teaching scenario and good teaching atmosphere, and rationally set teaching activities and contents in combination with the requirements for cultivating students' comprehensive quality, to provide qualified teacher guarantee for the cultivation of students' cooperative awareness in music learning. Only in this way, the music teachers of preschool education major can gradually develop the capability of cultivating students' cooperative awareness, and students' cooperative awareness can be constantly strengthened through systematic teaching practice.

\section{Cultivation of Students' Cooperative Awareness in Music Teaching Practice}

Cultivating students' cooperative awareness in music teaching is an important link of cultivating students' cooperative awareness. Only by letting students gradually touch cooperative thought and have learning activities based on cooperative idea in music learning, students' cooperative awareness can be cultivated well. Specifically, the music teachers of preschool education major can strengthen students' cooperative awareness through chorus training, musical appreciation, and music composition education.

Firstly, chorus training. Chorus training is an important part of music teaching of preschool education major, and has vital influence on strengthening of students' music quality. Hence, permeating cooperative education idea in chorus training can promote students to gradually improve their cooperative awareness ${ }^{[2]}$. In teaching practice, teachers can select specific programs for chorus training, during which students should independently learn the programs, and perform singing neatly together. This requires students to constantly improve their singing skills to reach the chorus standard. Thus, in the process of cooperating and communicating with others, students' cooperative awareness is bound to be strengthened, and their cooperative ability can be greatly developed, having certain positive influence on students' future development.

Secondly, appreciation teaching. Since appreciation teaching is a key component in music teaching activities of preschool education major, teachers should consciously cultivate students' cooperative awareness in appreciation teaching, to gradually strengthen students' musical cooperative awareness.

Lastly, music composition. Music composition holds an important position in music teaching of preschool education major. Students should master music composition skills, so as to create and compose music programs in combination with related contents in preschool education activities in future, and educate children in a proper way. Hence, the music teachers of preschool education major should consciously permeate cooperative education idea in music composition activities, to cultivate students' cooperative awareness in a scientific way ${ }^{[3]}$. Specifically speaking, on one hand, the setting of creation and composition teaching activities can largely arouse students' enthusiasm, make for creating a good learning atmosphere in classroom, and opportunities of independent learning and interaction and exchange for students, help students acquire a deep knowledge of cooperative learning through interaction and communication and learn others advantages to adjust their own music learning methods, and gradually strengthen students' learning ability. On the other hand, music itself is featured by second creation. That's to say, music performers can give full play to their imagination and association ability in music performing based on their identification and understanding of music. Thus, it can be considered that the process of performers finishing music performance itself is a process of second creation of music, and music performance is featured by group activity. Hence, teachers surely will require students to play different roles in music composition in music composition teaching, such as orchestral instruments player, singer, etc., to help students learn to complete music composition through cooperation, and achieve a good learning effect. 


\section{Cultivating Students' Cooperative Awareness by Creating Harmonious Learning Relationship}

In teaching practice, as long as teachers and students establish a good learning relationship, students will entrust teachers, actively cooperate in teaching activities organized by teachers, and develop their learning enthusiasm well, and a harmonious teaching atmosphere can be created, to achieve the maximum teaching effect while raising students' cooperative awareness ${ }^{[4]}$. Specifically, facing questions raised by students in music teaching of preschool education major, teachers should praise students having the courage to explore first, actively encourage students' to further the exploration of various questions on this basis, and guide students' exploration activities, to let students learn to solve problems via independent exploration and teamwork. Thus, students can establish a harmonious learning relationship with others by helping or asking favor from others in constant explorations, and a harmonious learning atmosphere can be created, to cultivate students' cooperative awareness subtly.

For example, in the teaching process of the lesson of $Y i Y u L e ~ L a$, the music teachers of preschool education major should organize students to discuss about their feelings with reasons after guiding students to finish music appreciation to promote students to establish a good learning relationship. In this process, some students appear to less eloquent but just can express their opinions with a word "good" because of insufficiency of music quality and lack of music terminology. Under such circumstances, to prevent students' losing heart and suffering from larger pressure, teachers can specially give instructions to such students, and help them answer questions by reminding them of terms and be recognized by other classmates ${ }^{[5]}$. Besides, to enhance the interaction and communication between students, teachers can ask students to express their viewpoints on teaching contents through group discussion in advance. In this way, the less capable students in respect of music quality can express their viewpoints under the help of other classmates, so that students can form the good habit of helping and asking favor from others, and achieve a good learning effect in a good learning atmosphere in classroom. It is thus clear that that teacher carry out proper education and guidance to students, and develop students' learning confidence with a friendly and kind attitude can create a good learning atmosphere, and further enhance students' cooperative awareness, having a positive influence on students' working life in future.

\section{Conclusion}

To sum up, with the progress of the time and the reform of talent training ideas, cultivating students' cooperative awareness has gradually become a necessary requirement for trait-oriented education. It is the same with the carrying out of music teaching activities of preschool education major. Only by cultivating students' cooperative awareness as the key content, and actively organizing related teaching activities to constantly enhance students' cooperative awareness, the comprehensive quality of preschool education majors can be cultivated well, and students can enjoy a solid guarantee for career development in future.

\section{Acknowledgments}

This paper belongs to the scientific research project of the Education Department of Fujian Province, titled "Research on Interactive Music Teaching of Preschool Education Major of Normal Colleges" and numbered JBS09204; and the Fujian provincial young and middle-aged teacher education scientific research project, titled "Research on Li Jinhui Children Music Teaching Thoughts from the Perspective of Preschool Education" and numbered JAS160656.

\section{References}

[1] Zhang Chaohua. Cultivation of Students' Cooperative Awareness in Music Teaching. Huazhang, 2014(3):261-261. 
[2] Guo Jie. Inquiry-based Teaching of Cultivating Students' Cooperative Awareness in Music Lessons. Education Teaching Forum, 2013(6):139-140.

[3] Wei Xuexiu. On Cooperation and Innovation in Music Teaching Course Education Research,2015(2):206-206.

[4] Wu Mali. Analysis of Positive Effect of Music Teaching on Students’ Psychological Health Art Education Research, 2014(12):92-92.

[5] Zheng Junqian. Brief Analysis of Cultivation of Students' Cooperative Awareness in Music Teaching. Art Education Research, 2015,35(15):127. 